\title{
Relative Abundance of a Vector of Scrub Typhus, Leptotrombidium sialkotense, in Southern Yunnan Province, China
}

\author{
Yan Lv', , Xian-Guo Guo ${ }^{1,2,3, *}$, Dao-Chao Jin', Wen-Yu Song'2, Rong Fan², Cheng-Fu Zhao², Zhi-Wei Zhang', \\ Ke-Yu Mao'2, Yun-Ji Zou'2, Zhi-Hua Yang ${ }^{2}$ \\ ${ }^{1}$ Institute of Entomology, Guizhou University, and the Provincial Key Laboratory for Agricultural Pest Management in Mountainous Region, Guiyang \\ 550025, China; ${ }^{2}$ Vector Laboratory, Institute of Pathogens and Vectors, Yunnan Provincial Key Laboratory for Zoonosis Control and Prevention, Dali \\ University, Dali, Yunnan Province 671000, China; ${ }^{3}$ Yunnan Provincial Key Laboratory of Entomological Biopharmaceutical Research and \\ Development, Dali University, Dali, Yunnan Province 671000, China
}

\begin{abstract}
The chigger mite Leptotrombidium sialkotense is one of the 6 main vectors of scrub typhus in China. Before present study, L. sialkotense was found in some parts of Hunan province, China with a narrow geographical distribution. During field investigation 2016-2017, we found L. sialkotense in Jingha, southern Yunnan, China. Of 15 small mammal host species, $L$. sialkotense were collected from 6 species of the hosts. Rattus brunneusculus was a dominant host of $L$. sialkotense, from which $98.3 \%$ of the mites were collected. The chigger mite showed a relatively high infestation prevalence $\left(P_{M}=11.7 \%\right)$ and mean abundance $(M A=0.5)$ in comparison with the rest 5 host species. These results reveal a certain host specificity of $L$. sialkotense to a rat $R$. brunneusculus. The mite $L$. sialkotense showed an aggregated distribution on the host $(P<0.05)$. A positive correlation observed between $L$. sialkotense and the body length of hosts. There was a positive interspecific association between $L$. sialkotense and 2 other dominant vectors, $L$. deliense and $L$. scutellare.
\end{abstract}

Key words: Leptotrombidium sialkotense, chigger mite, vector, scrub typhu, host selection, rodent

\section{INTRODUCTION}

Chigger mites refer to 2 taxonomic families (Trombiculidae and Leeuwenhoekiidae), and they belong to Acariformes, Acari, Arachnida under Arthropoda [1-3]. There are more than 3,700 species of chigger mites widely distributed in the world and more than 400 species found in China [3-5]. The larvae of chigger mites (chiggers) are the exclusive vector of scrub typhus (tsutsugamushi disease) and they are the only ectoparasitic and disease-transmitting stage in their complex life cycle [6,7]. The taxonomic identification of chigger mites has long been based on the morphology of the larvae. Rodents and some other small mammals are the most important hosts of the larvae (chiggers). Scrub typhus transmitted by chiggers is widely distributed in many parts of China, especially in the

\footnotetext{
- Received 5 December 2019, revised 20 February 2020, accepted 24 February 2020. *Corresponding author (xianguoguo@yahoo.com) (C) 2020, Korean Society for Parasitology and Tropical Medicine This is an Open Access article distributed under the terms of the Creative Commons Attribution Non-Commercial License (https://creativecommons.org/licenses/by-nc/4.0) which permits unrestricted non-commercial use, distribution, and reproduction in any medium, provided the original work is properly cited.
}

south [8-10]. Located in the southwest of China, Yunnan province is one of main foci of scrub typhus in China, with the distribution of the disease in all the 16 prefectures and municipalities of the province. Of total 129 counties in 16 prefectures and municipalities of Yunnan province, 118 counties have the cases of scrub typhus reported $[10,11]$. As an independent species of chigger mites, Leptotrombidium sialkotense is one of the 6 main vectors of scrub typhus in China, and it plays an important role in the transmission of the disease $[1,12]$. VercammenGrandjean and Langston [2] first named Leptotrombidium (Leptotrombidium) imphalum sialkotense in 1976. After that some Chinese scholars described a new species of chigger mite, Leptotrombidium (Leptotrombidium) jishoum in 1988 [13], which was afterwards proved to be the synonymous species of $L$. (L.) imphalum sialkotense and was finally revised to Leptotrombidium sialkotense [14]. Leptotrombidium sialkotense was first found in Jishou of Hunan province in 1988. Before this study, Chinese scientists generally thought that $L$. sialkotense was an endemic species of chigger mite in some parts of China with a very narrow geographical distribution and it was mainly confined to Jishou, Guzhang and Baojing in Hunan province. During the 
investigation on chigger mite distribution in Yunnan province, we found $L$. sialkotense at Jingha village, Jinghong county of Xishuangbanna Dai Autonomous prefecture in southern Yunnan, where is far from the original distribution areas of L. sialkotense. The distribution of $L$. sialkotense at Jingha village is the first report of the mite in the whole Yunnan province, which is of academic significance.

\section{MATERIALS AND METHODS}

\section{Field investigation}

From a field investigation from April 2016 to March 2017, Leptotrombidium sialkotense was found at a localized area, Jingha village in Jinghong county of Xishuangbanna Dai Autonomous prefecture in southern Yunnan, southwest China. Jingha village is near the coast of the Lancang river (a river from the northwest to the south in Yunnan province), and located at $21^{\circ} 50^{\prime}$ north latitude and $100^{\circ} 52^{\prime}$ east longitude with an altitude of 500-700 $\mathrm{m}$ [15]. The village is a rubber planting area with lots of rubber woodlands dotted with some banana fields, farmlands, bush areas and broad-leaved forests.

\section{Collection of chigger mites and their hosts}

In field survey, the mousetraps were set to capture the host animals (rodents and some other small mammals) in evening and checked in the next morning. Each captured host was put into a separate cloth bag and brought to the laboratory where the host was anaesthetized with ether. Each anaesthetized host was carefully examined and chiggers were collected mainly from the both auricles and external auditory canals of each host, where chiggers often attached. All the collected chiggers from each host were separately preserved in a vial with $70 \%$ of ethanol. After the collection of chiggers, every host was identified into species according to its external morphological characteristics and various comprehensive measurement indexes [16-18].

\section{Identification of chigger mites}

Every chigger was slide-mounted with Hoyer's medium and it was finally identified into a species according to identification keys under a microscope after dehydration and transparent process $[2,3,14]$. According to the identification characteristics [14], the specimens suspected of L. sialkotense were confirmed one by one under high magnification and oil microscopes. From the identified samples of chigger mites, L. sialko- tense mite was chosen as the target for the further statistical analyses in this paper.

\section{Infestation calculation}

The constituent ratio $(\mathrm{Cr})$, prevalence $\left(P_{M}\right)$, mean abundance $(M A)$, and mean intensity $(M I)$ were used to calculate the infestation of L. sialkotense on its hosts, rodents and some other small mammals [1,19-21].

$$
C_{r}=\frac{N_{i}}{N} \times 100 \% ; P_{M}=\frac{H_{m}}{H} \times 100 \% ; M A=\frac{M}{H} ; M I=\frac{M}{H_{m}}
$$

$N_{i}$ and $N$ are the individuals of chigger mite species $i$ and all the mite species; $M, H_{m}$, and $H$ the individuals of $L$. sialkotense, infested hosts and all the hosts [1,19-21].

\section{Spatial pattern analysis}

With the combination of a random deviation test ( $F$ test), Iwao's regression equation was used to analyze the spatial distribution pattern of L. sialkotense on 6 hosts [22-24]. The formulas are as follows:

$$
\begin{aligned}
& M^{*}=\alpha+\beta M \text { (Iwao's linear regression) } \\
& F=\frac{\frac{1}{2}\left[N \alpha^{2}+2 \alpha(\beta-1) \sum_{i=1}^{N} M_{i}+(\beta-1)^{2} \sum_{i=1}^{N} M_{i}{ }^{2}\right]}{\frac{1}{N-2} \sum_{i=1}^{N}\left(M_{i}^{*}-\alpha-\beta M_{i}\right)^{2}} \\
& M_{i}=\frac{\sum_{j=1}^{N_{i}} M_{i j}}{N_{i}} ; M_{i}^{*}=M_{i}+\left(\frac{\sigma_{i}^{2}}{M_{i}}-1\right)
\end{aligned}
$$

In Iwao's regression, $M$ and $M^{*}$ are the mean and mean crowding of the mites (L. sialkotense); $\alpha$ and $\beta$ the intercept and regression coefficient. In $F$ test, $M_{i j}$ and $N_{i}$ are the individuals of the mites and hosts in sampling unit $i$, and $M_{i}$ and $\sigma^{2}{ }_{i}$ the mean and variance. The aggregated distribution is determined when $\alpha>1$ and $\beta>1\left(F>F_{0.05}(2, \mathrm{~N}-2), P<0.05\right)[22-24]$.

\section{Statistical analysis on ecological niche}

Based on the constituent ratio, Levins' niche breadth was adopted to evaluate the host-specificity $[16,21,25]$.

$$
B_{i}=\frac{1}{S \sum_{h=1}^{S} P_{i h}{ }^{2}}
$$

$B_{i}$ is the niche breadth of $L$. sialkotense; $P_{i h}$ and $S$ the constituent ratio of the mites on different host species and total host species $[16,21,25]$. 


\section{Some other statistical analyses}

Mann-Whitney U-tests were used to detect the difference in the individuals of $L$. sialkotense among different genders and ages of hosts. The correlation between the number of $L$. sialkotense mites and the host parameters (body weight, body length) was analyzed by Pearson coefficient. The coefficient of
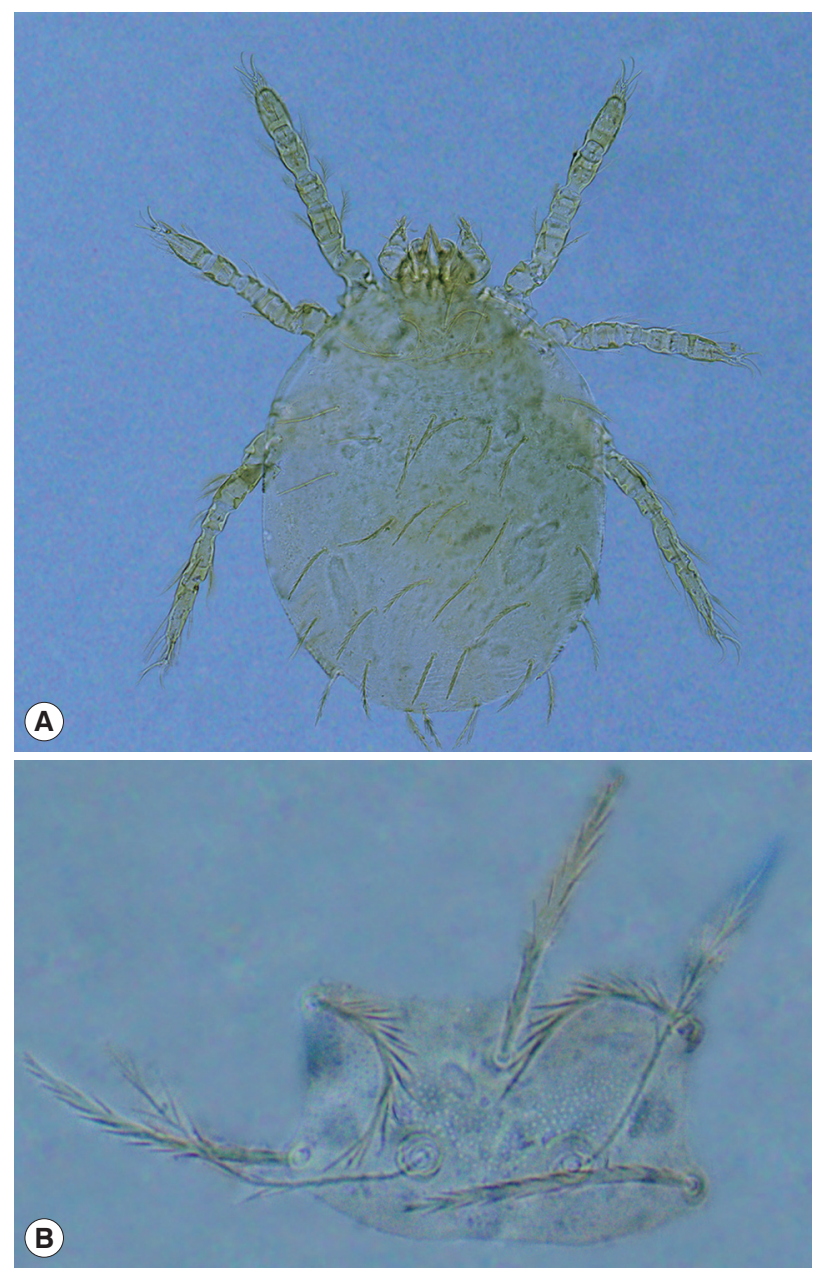

Fig. 1. Morphology of Leptotrombidium sialkotense. (A) Larva (10 $\times 20)$. (B) scutum $(10 \times 40)$. association $(V)$ was used to analyze the interspecific relationship between $L$. sialkotense and some other chigger mites $[26,27]$.

$$
V=\frac{a d-b c}{\sqrt{(a+b)(c+d)(a+c)(b+d)}}
$$

Where $a, b, c$ and $d$ represent host individuals; $a$ means the hosts with both $X$ and $Y$ mite species, $d$ without both $X$ and $Y$, and $b$ and $c$ with either $X$ or $Y$. When $0<V \leq 1(P<0.05)$, a positive association is determined while the opposition $(-1 \leq V<0, P<0.05)$, the negative association $[26,27]$.

\section{RESULTS}

\section{Chigger mite $L$. sialkotense and hosts}

A total of 2,434 rodents and some other small mammal hosts were captured from the field investigation at Jingha village from 2016 to 2017. Of the 2,434 captured hosts, 2,424 of them were identified as 15 species, 10 genera and 5 families under 4 orders, and the rest 10 hosts remained unidentified because of their morphological variations. A total of 109,199 chiggers were identified as 109 species, 12 genera and 2 subfamilies (Trombiculinae and Gahrliepiinae) in the family Trombiculidae.

Table 2. Calculation of $M$ and $M^{*}$ in measurement of spatial pattern of Leptotrombidium sialkotense on small mammal hosts

\begin{tabular}{lcc}
\hline \multirow{2}{*}{ Host species } & \multicolumn{2}{c}{ L. sialkotense } \\
\cline { 2 - 3 } & $M$ & $M^{*}$ \\
\hline R. brunneusculus & 0.5 & 21.2 \\
R. tanezumi & 0.0 & 1.8 \\
B. bowersi & 0.0 & 0.0 \\
H. suillus & 0.2 & 1.2 \\
T. belangeri & 0.4 & 4.4 \\
N. fulvescens & 0.1 & 2.1 \\
\hline
\end{tabular}

$M$ : the mean of the mite individuals (L. sialkotense).

$M^{\star}$ : the mean crowding of the mite individuals.

Table 1. Infestation of Leptotrombidium sialkotense on the hosts in Jingha, southern Yunnan, China (2016-2017)

\begin{tabular}{|c|c|c|c|c|c|c|}
\hline \multirow{2}{*}{ Host species } & \multicolumn{2}{|c|}{ No. of hosts } & \multicolumn{4}{|c|}{ L. sialkotense on hosts } \\
\hline & Examined & Infested (\%) & No. of Mite & Constituent ratio (\%) & Mean abundance & Mean intensity \\
\hline Rattus brunneusculus & 2,053 & 11.7 & 1,118 & 98.3 & 0.5 & 4.7 \\
\hline Rattus tanezumi & 186 & 1.6 & 8 & 0.7 & 0.0 & 2.7 \\
\hline Berylmys bowersi & 57 & 1.8 & 1 & 0.1 & 0.0 & 1.0 \\
\hline Hylomys suillus & 10 & 10.0 & 2 & 0.2 & 0.2 & 2.0 \\
\hline Tupaia belangeri & 14 & 7.1 & 5 & 0.4 & 0.4 & 5.0 \\
\hline Niviventer fulvescens & 61 & 1.6 & 3 & 0.3 & 0.1 & 3.0 \\
\hline Total & 2,381 & 10.4 & 1,137 & 100 & 0.5 & 4.6 \\
\hline
\end{tabular}


Table 3. Interspecific relationship among Leptotrombidium sialkotense, L. deliense and L. scutellare on Rattus brunneusculus in Jingha, southern Yunnan, southwest China

\begin{tabular}{|c|c|c|c|c|c|c|}
\hline & \multicolumn{2}{|c|}{ L. deliense } & \multirow{2}{*}{ Subtotal } & \multicolumn{2}{|c|}{ L. scutellare } & \multirow{2}{*}{ Subtotal } \\
\hline & + & - & & + & - & \\
\hline \multicolumn{7}{|l|}{ L. sialkotense } \\
\hline+ & 226 & 14 & 240 & 107 & 133 & 240 \\
\hline- & 1,185 & 628 & 1,813 & 355 & 1,458 & 1,813 \\
\hline Total & 1,411 & 642 & 2,053 & 462 & 1,591 & 2,053 \\
\hline Association coefficient & \multicolumn{2}{|c|}{0.20} & \multicolumn{4}{|c|}{0.19} \\
\hline Significance & \multicolumn{2}{|c|}{$P<0.001$} & \multicolumn{4}{|c|}{$P<0.001$} \\
\hline
\end{tabular}

After repeated identification and recheck of the specimens, there were 1,137 mites confirmed as L. sialkotense (Fig. 1) from the collected 109,199 chigger mites. Most of L. sialkotense mites were collected from rubber woodlands, accounting for $98.1 \%$. The L. sialkotense mites were collected from 6 species of small animals including 4 rodent species (Rattus brunneusculus, $R$. tanezumi, Berylmys bowersi, Nivivanter fulvalescens), one insectivore (Hylomys suillus) and one tree shrew (Tupaia belangeri).

\section{Host preference of $L$. sialkotense}

Among 1,137 L. sialkotense, 98.3\% were collected from the southeast Asian house rat ( $R$. brunneusculus), and infection indexes were higher (Table 1). Based on calculation results of $M$ and $M^{*}$ in measurement of spatial pattern of L. sialkotense on 6 species of small mammal hosts (Table 2), an Iwao's regression equation was established as $M^{*}=-1.5+32.8 M(\alpha=-1.5$, $\beta=32.8, r=0.87, P<0.05)$. According to the criteria, a calculated $F$ value $(F=9.17)$ was higher than $F_{0.05(2,4)}\left(F_{0.05}(2,4)=6.94\right)$ with statistical significance $(P<0.05)$. A spatial distribution pattern of L. sialkotense on 6 host species was determined to be aggregated distribution. Value of Levin's niche breadth of $L$. sialkotense was very low $\left(B_{i}=6.89462 \mathrm{e}^{-6}\right)$. Host selection of $L$. sialkotense on host genders showed that $L$. sialkotense was inclined to choose female hosts, but the difference has no statistical significance (Supplementary Table S1). Most of L. sialkotense mites tend to choose adult hosts, and difference of $P_{M}$ and $M I$ on different host ages was of statistical significance (Supplementary Table S2). There were positive correlations between the individuals of $L$. sialkotense and the body weight $(r=0.10, P<0.05)$ and body length $(r=0.14, P<0.05)$.

\section{Interspecific relationship of $L$. sialkotense with $L$. deliense and $L$. scutellare}

Association coefficient $(V)$ between $L$. sialkotense and 2 other chigger mites ( $L$. deliense and $L$. scutellare) showed a positive association ( $L$. sialkotense and $L$. deliense: $V=0.20, P<0.05 ; L$. sialkotense and $L$. scutellare: $V=0.19, P<0.05)$ (Table 3$)$.

\section{DISCUSSION}

In China, 6 species of chigger mites have proved to be the main transmitting vectors of scrub typhus, and they are Leptotrombidium deliense, L scutellare, L. sialkotense (L. jishoum), L. rubellum, L.wenense (L. kaohuense) and L. insulare [12,28]. Apart from the 6 main vector species, there are more than 10 other potential vector species in China and they are L. guzhangense, $L$. fujii, L. yui, L. orientale, L. apodemi, L. intermedium, L. linhuaikongense, L. imphalum, L. akamushi, L. pallidum, L. rupestre, $L$. parapalpale, L. cricethrionis (L. rusticum) and $L$. palpale $[10,12,25]$. Of the 6 main vector species, L. jishoum is the synonymous name of L. sialkotense and L. kaohuense is the synonymous name of L.wenense [14], but they have long been mistakenly used in China $[12,13,28]$. In this paper, we formally revised $L$. jishoum to L. sialkotense and L. kaohuense to L.wenense [14]. As an independent species of chigger mites within the genus Leptotrombidium, L. sialkotense (L. jishoum) has some essential morphological characteristics for its identification [14]. Before the present study, L. sialkotense (L. jishoum) was found only in Hunan province and it was a main vector of scrub typhus [13]. There was no report on L. sialkotense (L. jishoum) from other parts of China. Present paper first reported existence and distribution of $L$. sialkotense at Jingha village in southern Yunnan. Southern Yunnan is far away from Hunan province. The existence of $L$. sialkotense in southern Yunnan suggests that this species of chigger mite is not only limited to Hunan province, but also some other parts of China. Our investigation, however, is just a preliminary study and more field investigations remain to be made to reveal the complete geographical distributions of L. sialkotense.

The investigation site (Jingha) belongs to a flatland land- 
scape along Lancang river has $18.6-21.9^{\circ} \mathrm{C}$, annual average temperature, 1,200-1,700 mm annual precipitation and 80$86 \%$ annual relative humidity $[1,29,30]$. Warm and humid environment here, together with rich vegetation, fertile soil and sunshine, are considered beneficial to the reproduction of most chigger mites and their host animals. This ecosystem may provide ideal places for most chigger mite species [8,31]. Like most species of chigger mites, $L$. sialkotense may tend to distribute in some warm and humid areas. It was reported that L. sialkotense distributed in some tropical regions like Thailand and Pakistan [14,32]. It may further imply that $L$. sialkotense is preferenial to the warm and humid environment.

Before the present study, L. deliense was traditionally considered to be the predominant or exclusive vector of scrub typhus throughout the whole Yunnan province $[33,34]$. In recent years, however, some other vector species of scrub typhus have successively been reported to be distributed in Yunnan province such as L. scutellare and L. rubellum, and more and more evidences have revealed that a few vector species of scrub typhus coexist in Yunnan $[1,21,35]$. The existence and relative abundance of L. sialkotense in southern Yunnan may further support the coexistence of mixed vector species of chigger mites in the province.

In our investigation at Jingha Village (a localized investigation site), we totally examined 15 species and 2,434 individuals of small animal hosts, including rodents and some other small mammals. The chigger mite L. sialkotense was found on only the 6 species of the examined 15 host species. From the 247 individuals of all the examined 2,434 animal hosts, a total of 1,137 L. sialkotense chiggers were collected, and $98.3 \%$ of $L$. sialkotense mites were from the southeast Asian house rat, $R$. brunneusculus. The other 5 hosts were R. tanezumi, B. bowersi, $N$. fulvescens, $H$. Suillus and T. belangeri respectively. The results suggest that $L$. sialkotense do not parasite all the animal hosts in a certain area, and it has some host preference and host specificity. At the investigation site (Jingha Village) of southern Yunnan, the dominant host of L. sialkotense is the southeast Asian house rat, $R$. brunneusculus. The very low niche breadth of $L$. sialkotense in this paper, together with the fact that $98.3 \%$ of $L$. sialkotense were collected from R. brunneusculus, may further support that $L$. sialkotense has some host preference and host specificity because niche breadth is usually opposite to host specificity, the lower the niche breadth, the higher the host specificity [21,25].

Some previous studies reported that the host range of L. si- alkotense covered a lot of some other animal species including Apodemus agrarius, R. norvegicus, Suncus sp., R. nitidus, S. murinus, Microtus fortis calamorum and Tupaia glis $[13,14,32,36]$. The results in our study added the host range of $L$. sialkotense, and the newly recorded host species are $R$. brunneusculus, $R$. tanezu$m i$, B. bowersi, N. fulvescens, H. Suillus and T. belangeri. The results imply that $L$. sialkotense can parasitize a variety of animal hosts although it has a certain host specificity and its hosts (including the dominant host) may vary from region to region.

The spatial distribution pattern of L. sialkotense on 6 species of hosts was determined as aggregated distribution. The aggregated distribution is an uneven distribution and it suggests that some hosts harbor few or no mites while some others harbor abundant mites $[6,37]$.

The results showed that $L$. sialkotense was more likely to choose adult hosts and this is consistent with some previous reports $[37,38]$. Although the individuals of $L$. sialkotense showed very slightly positive correlations with the body weight and body length of its hosts $(P<0.05)$, the correlation coefficients was too low $(r=0.10 ; r=014)$ and this relationship may need a further study. A slight positive association existed between $L$. sialkotense and 2 other dominant vectors (L. deliense: $V=0.20$; L. scutellare: $V=0.19$ ), but the association coefficient was also too low and more researches remain to be made.

\section{ACKNOWLEDGMENTS}

We would express our sincere thanks to the following people who gave some helps in the field investigation and laboratory work: Sheng-Zhen Li, He Sha, some colleagues and college students in Dali University. This study was financially supported by the National Natural Science Foundation of China to Xian-Guo Guo (No. 81672055, 81960380), the Academician Workstation for Academician Jian-Guo Xu and the Innovation Team of Vector Biology, Dali University (No. ZKLX2019104). We would also express our special thanks to the above financial supports.

\section{CONFLICT OF INTEREST}

The authors declare that they have no conflict of interest related to this study. 


\section{REFERENCES}

1. Peng PY, Guo XG, Jin DC, Dong WG, Qian TJ, Qin F, Yang ZH. New record of the scrub typhus vector, Leptotrombidium rubellum, in southwest China. J Med Entomol 2017; 54: 1767-1770.

2. Vercammen-Grandjean PH, Langston RL. The Chigger Mites of the World (Acarina: Trombiculidae \& Leeuwenhoekiidae). III. Leptotrombidium Complex. San Francisco, USA. George Williams Hooper Foundation. 1976, pp 1-1061.

3. Li JC, Wang DQ, Chen XB. Trombiculid Mites of China: Studies on Vector and Pathogen of Tsutsugamushi Disease. Guangzhou, China. Guangdong Science and Technology Publishing. 1997, pp 1-157 (in Chinese).

4. Ren TG, Guo XG, Jin DC, Wu D, Fletcher QE. A new species of chigger mite (Acari: Trombiculidae) from rodents in southwest China. Korean J Parasitol 2014; 52: 63-67.

5. Zhang ZQ. Animal biodiversity: an outline of higher-level classification and survey of taxonomic richness. In Zhang ZQ, Fan QH, Pesic V, Smit H, Bochkov AV, Khaustov AA, Baker A, Wohltmann A, Wen TH, Amrine JW, Beron P, Lin JZ, Gabrys G, Husband R eds, Order Trombidiformes Reuter, 1909. Auckland, New Zealand. Magnolia Press. 2011, pp. 129-138.

6. Peng PY, Guo XG, Song WY, Hou P, Zou YJ, Fan R. Ectoparasitic chigger mites on large oriental vole (Eothenomys miletus) across southwest, China. Parasitol Res 2016; 115: 623-632.

7. Shatrov AB, Kudryashova NI. Taxonomy, life cycles and the origin of parasitism in trombiculid mites. In Morand S, Krasnov BR, Poulin R eds, Micromammals and Macroparasites. Tokyo Springer. Tokyo, Japan. 2006, pp 119-140.

8. Lv Y, Guo XG, Jin DC. Research progress on Leptotrombidium deliense. Korean J Parasitol 2018; 56: 313-324.

9. Geng ML, Guo XG. Advances in the study of Leptotrombidium deliense in China. J Pathogen Biol 2014; 9: 763-765.

10. Su JJ, Wang Y, Zhou J, Bin Y, Yang ZQ. Advances in research of tsutsugamushi disease epidemiology in China in recent years. Chin J Hyg Insect Equip 2012; 18: 160-163.

11. Yuan QH, Chen M, Yang XD. Epidemiological analysis of scrub typhus in Yunnan province during 2006-2017. Chin J Vector Biol Control 2018; 29: 69-72.

12. Wu GH, Jiang ZK, Wang L, Ding LY, Mao CQ, Ma BY. Accordance and identification of vector chigger mites of tsutsugamushi disease in China. Chin J Hyg Insect Equip 2013; 19: 286-292 (in Chinese).

13. Wen TH, Li GM, Zhang XX, Liao HR. A new species of sand mite from the western part of Hunan province, China (Acariformes: Trombiculidae). Entomotaxonomia 1988; 10: 107-113.

14. Stekolnikov AA. Leptotrombidium (Acari: Trombiculidae) of the world. Zootaxa 2013; 3728: 1-173.

15. Sun KZ, Qiao YG, Qin BZ. A green pearl of the southwestern frontier of China-the topography, climate, plant species and collection of Xishuangbanna. Biol Teach 2000; 25: 37-38.

16. Peng PY, Guo XG, Ren TG, Song WY. Faunal analysis of chigger mites (Acari: Prostigmata) on small mammals in Yunnan prov- ince, southwest China. Parasitol Res 2015; 114: 2815-2833.

17. Wilson DE, Reeder DM. Mammal Species of the World: A Taxonomic and Geographic Reference. 3rd ed. Baltimore, USA. Johns Hopkins University Press. 2005.

18. Kia E, Moghddas-Sani H, Hassanpoor H, Vatandoost H, Zahabiun F, Akhavan A, Hanafi-Bojd A, Telmadarraiy Z. Ectoparasites of rodents captured in Bandar Abbas, southern Iran. Iran J Arthropod Borne Dis 2009; 3: 44-49.

19. Bush AO, Lafferty KD, Lotz JM, Shostak AW. Parasitology meets ecology on its own terms: Margolis et al. revisited. J Parasitol 1997; 83: 575-583.

20. Margolis L, Esch GW, Holmes JC, Kuris AM, Schad GA. The use of ecological terms in parasitology (Report of an ad hoc committee of the American Society of Parasitologists). J Parasitol 1982; 68: 131-133.

21. Peng PY, Guo XG, Jin DC, Dong WG, Qian TJ, Qin F, Yang ZH. Species abundance distribution and ecological niches of chigger mites on small mammals in Yunnan province, southwest China. Biologia 2017; 72: 1031-1040.

22. Guo XG. Spatial pattern analysis of Laelaps echidninus and Laelaps nuttalli using Iwao's method and a significance test of random deviation (Acari: Laelapidae). Syst Appl Acarol 1997; 2: 89-93.

23. Iwao S. A new regression method for analyzing the aggregation pattern of animal populations. Res Popul Ecol 1968; 10: 1-20.

24. Lv Y, Guo XG, Jin DC, Song WY, Fan R, Zhao CF, Zhang ZW, Mao KY, Peng PY, Lin H, Zhao Y, Qian TJ, Dong WG. Host selection and seasonal fluctuation of Leptotrombidium deliense (Walch, 1922) (Trombidiformes: Trombiculidae) at a localized area of southern Yunnan, China. Syst Appl Acarol 2019; 24: 2253-2271.

25. Guo XG. Host-specificity and host-selection of gamasid mites (Acari: Gamasina). Syst Appl Acarol 1998; 3: 29-34.

26. Guo XG, Qian TJ, Meng XY, Dong WG, Shi WX, Wu D. Preliminary analysis of chigger communities associated with house rats (Rattus flavipectus) from six counties in Yunnan, China. Syst Appl Acarol 2006; 11: 13-21.

27. Guo XG, Gu YM. A study on interspecific relationship among several dominant species of gamasid mites. J Guiyang Med Coll 1990; 15: 116-120.

28. Wu GH. Research on the vector of scrub typhus in China. Chin J Vector Bio Control 2005; 16: 485-487.

29. Wang QH, Shi AM, Guo XG, Song WY, Zhao N, Dong WG. Investigation of chigger mites on small mammals in a flatland area of Menghan, Xishuangbanna, Yunnan province. Chinese J Parasitol Parasit Dis 2013; 31: 303-306 (in Chinese).

30. Yu Y, Meng GY, Zhang CL. Characteristics of climate change in Xishuangbanna area in the past 45 years. Meteorol Sci 2008; 36 : 410-413.

31. Zhang WY, Wang LY, Ding F, Hu WB, Soares MR, Sun HL, Liu YX, Liu QY, Huang LY, Clements AC, Li SL, Li CY. Scrub typhus in mainland China, 2006-2012: the need for targeted public health interventions. PLoS Negl Trop Dis 2013; 7: e2493.

32. Chaisiri K, Stekolnikov AA, Makepeace BL, Morand S. A revised checklist of chigger mites (Acari: Trombiculidae) from Thailand, 
with the description of three new species. J Med Entomol 2016; 53: 321-342.

33. Zhan YZ, Guo XG, Speakman JR, Zuo XH, Wu D, Wang QH, Yang ZH. Abundances and host relationships of chigger mites in Yunnan Province, China. Med Vet Entomol 2013; 27: 194-202.

34. Yang GR, Yu ZZ, Xie BQ. Research on the biology of Leptotrombidium deliense in Yunnan province. Chin J Pest Control 1991; 7: $7-12$.

35. Peng PY, Guo XG, Ren TG, Dong WG, Song WY. An updated distribution and hosts: Trombiculid mites (Acari: Trombidiformes) associated with small mammals in Yunnan Province, southwest China. Parasitol Res 2016; 115: 1923-1938.

36. Li GM, Wang Y, Liao FY. Relationship between the distribution of the epidemic focus of tsutsugamushi disease and the inversion layer in mountain area in western Hunan Province. Hunan Journal 1996; 13: 161-162.

37. Peng PY, Guo XG, Song WY, Hou P, Zou YJ, Fan R, He XS. Analysis of ectoparasites (chigger mites, gamasid mites, fleas and sucking lice) of the Yunnan red-backed vole (Eothenomys miletus) sampled throughout its range in southwest China. Med Vet Entomol 2015; 29: 403-415.

38. Guo XG, Speakman JR, Dong WG, Men XY, Qian TJ, Wu D, Qin F, Song WY. Ectoparasitic insects and mites on Yunnan redbacked voles (Eothenomys miletus) from a localized area in southwest China. Parasitol Res 2013; 112: 3543-3549. 
